\title{
Comparison of intraoperative bleeding and surgical fields with and without tranexamic acid in Functional endoscopic sinus surgery
}

\author{
Dhanashree H. Dongare $^{1, *}$, Girish Y. Saundattikar ${ }^{2}$ \\ ${ }^{1}$ Associate Professor, ${ }^{2}$ Professor \& HOD, Dept. of Anaesthesia and Critical Care, Smt. Kashibai Navale Medical College and \\ General Hospital, Pune, Maharashtra, India
}

*Corresponding Author:

Email: dhanashreedongare@gmail.com

Received: $03^{\text {rd }}$ July, 2017

Accepted: $12^{\text {th }}$ October, 2017

\begin{abstract}
Functional endoscopic sinus surgery (FESS) requires good intraoperative surgical field visualization for better identification of structures. Among the many modalities for improving visibility, antifibrinolytic agent like Tranexamic acid has shown good results in many other surgeries. In this study, we have evaluated the effect of a single bolus dose of $15 \mathrm{mg} / \mathrm{kg}$ intravenous Tranexamic acid when used as an adjunct.

Materials and Methods: We have studied group $\mathrm{T}(\mathrm{n}=30)$, who received Inj. Tranexamic acid against group C ( $=30)$ i.e. control group. They were compared for surgical field using Boezaart scale, surgical duration and blood loss. Statistical analysis was done by unpaired t test and chi square test as was appropriate.

Results: T group showed significantly lower values of Boezaart scale score i.e. better visualisation for surgical field ( $\mathrm{p}<0.001$ ). Blood loss was also less in T group $(103 \pm 23.97 \mathrm{ml})$ as against group C $(150 \pm 62.33 \mathrm{ml})$. The duration of surgery was $53.83 \pm 8.57$ minutes in group $\mathrm{T}$ and $62.3 \pm 11.8$ minutes in group $\mathrm{C}$. Both the differences were statistically significant.

Conclusion: We found that Tranexamic acid has a beneficial role in functional endoscopic sinus surgeries by improving the quality of surgical field when used as an adjunct.
\end{abstract}

Keywords: Tranexamic acid, surgical field, functional endoscopic sinus surgery.

\section{Introduction}

Functional endoscopic sinus surgery (FESS) is now increasingly performed for chronic sinusitis not responding to medical treatment and for nasal polyposis. Poor intraoperative surgical field reduces visibility, makes identification of structures difficult and prolongs operative time. At times it may lead to incomplete surgery. Antifibrinolytic agent like Tranexamic acid in various doses and infusions has shown good results for improving surgical field and reducing bleeding in FESS as well as other surgeries like total knee replacement, scoliosis repair etc. In this study we have evaluated the effect of a single bolus dose of $15 \mathrm{mg} / \mathrm{kg}$ intravenous Tranexamic acid as an adjuvant for improvement of surgical field during FESS.

\section{Materials and Methods}

After approval from institutional ethical committee, 60 ASA grades I and II patients aged 18-60 years, posted for functional endoscopic sinus surgery for nasal polyposis were enrolled for the study. A written, valid and informed consent was obtained from all patients. They were randomly assigned to either Tranexamic acid group $(T) n=30$, or control group (C) $\mathrm{n}=30$. Patients having cardiorespiratory illness, hypertention, asthma, obesity (BMI>30), known coagulopathies, those on anticoagulants, antiplatelets or NSAIDs, those having history of deep vein thrombosis, stroke, ischemic heart disease, peripheral vascular disease, those having active hematuria, those with history of convulsive disorders, patients on oral contraceptives and patients with psychiatric illness were excluded from study.

After thorough preoperative assessment, randomization was done by a random number table. Upon arrival in operation theatre, standard monitors like electrocardiogram (ECG), non invasive blood pressure (NIBP) and pulse oximetry were attached and baseline values of pulse rate and mean arterial pressure were noted. Intravenous line was secured and Ringers lactate solution was started. Premedication was given with Inj. Midazolam $0.03 \mathrm{mg} / \mathrm{kg}$ and Inj Fentanyl $2 \mathrm{mcg} / \mathrm{kg}$ iv, Inj. Glycopyrrolate $4 \mathrm{mcg} / \mathrm{kg}$ and Inj. Ondansetron $4 \mathrm{mg}$ intravenously. Patients in group $\mathrm{T}$ received inj. Tranexamic acid $15 \mathrm{mg} / \mathrm{kg}$ as a slow intravenous bolus and patients with group $\mathrm{C}$ received $10 \mathrm{ml}$ normal saline by an observer blinded to the contents of the syringes. General anaesthesia was induced with Inj Propofol, in induction dose (till the loss of eyelash reflex) and Inj. Vecuronium $0.1 \mathrm{mg} / \mathrm{kg}$ was given to facilitate intubation with appropriate sized Portex cuffed entotracheal tube. An end tidal $\mathrm{CO} 2$ (ETCO2) monitor was attached to the endotracheal tube and mechanical ventilation was initiated. Throat packing was done with appropriate sized moistened roller gauze. Head up position by $15^{0}$ was given to both the groups. Anesthesia was maintained with $\mathrm{O} 2: \mathrm{N} 2 \mathrm{O}$ (50:50) and Isoflurane titrated to keep the systolic blood pressure between $90-100 \mathrm{~mm}$ of $\mathrm{Hg}$ and a mean arterial 
pressure more than $60 \mathrm{~mm}$ of $\mathrm{Hg}$. The surgeon then infiltrated the field with 5-6 ml of 2\% Lignocaine with Adrenaline (1:200000).Blood pressure and heart rate were recorded every 15 minutes during the surgery and then immediately after recovery. End tidal co2 was monitored every 15 minutes intraoperatively. The surgeries were performed by same surgical team using the same techniques and instruments. The surgeons who were blinded to the use of Tranexamic acid, assessed the quality of the surgical field at 15, 30, 45 and 60 mins after starting the surgical procedure with a predefined scale adapted from that of Boezaart et al. ${ }^{1}$ as follows:

$0=$ No bleeding

1 = Minimal bleeding: Not a surgical nuisance and no suction required

2 = Mild bleeding: Occasional suction required, but does not affect dissection

3 = Moderate bleeding: Slightly compromises surgical field, frequent suction required

4 = Severe bleeding: Significantly compromises

surgical field, frequent suction required, bleeding threat field just after removal of suction

5 = Massive bleeding: Prevent dissection.

Blood loss was estimated by weighing sponges and measuring operative suction volume. Upon completion of surgical procedure, nose was packed by surgeons. Anesthetic agents were discontinued and neuromuscular blockade was reversed with Inj. Neostigmine $0.04 \mathrm{mg} / \mathrm{kg}$ and Inj. Glycopyrollate 0.01 $\mathrm{mg} / \mathrm{kg}$ body weight. After meeting the required criteria, oral suctioning and throat pack removal, patients were extubated. Post-operative care was carried out according to usual institutional protocols. Post operatively, patients were monitored for any side effects like nausea, vomiting, hypotention, pruritus, convulsions and hemorrhagic or thrombotic complications for 24 hours. They were observed for any signs or symptoms suggesting any thrombotic complication till their discharge.

\section{Statistical analysis}

We have used $\alpha=0.05$ with a power $(1-\beta)$ of 0.9 with regards to the study conducted by Eldaba AA et $\mathrm{al}^{2}$ using the surgical area bleeding score as the main response variable. We have studied 30 patients per group. Continuous data was analysed by unpaired t-test and categorical data by chi square test. A p- value of $>0.05 \%$ was considered significant.

\section{Results}

Demographic parameters of age, sex and weight were comparable in both groups (Table 1). Intraoperative mean arterial blood pressure and ETCO2 were also comparable in both groups (Table 2). Surgical field score is shown in Table 3 as the number of patients from each group having a particular score. The recordings made at 15,30 and 45 minutes of surgery are shown. There is a clinically as well as statistically significant better score in group $\mathrm{T}$ as compared to group C. None of the patients in either group had a score of 5, i.e. massive bleeding preventing any dissection. The intraoperative blood loss and surgical duration are shown in table 4 . Both the parameters were significantly less in group T. No postoperative complication like nausea, vomiting, pruritus, convulsions or any thrombotic event was noted.

Table 1: Demographic parameters

\begin{tabular}{|l|c|c|c|}
\hline \multicolumn{1}{|c|}{ Variable } & Group T & Group c & P-value \\
\hline Age (years) & $39.03( \pm 8.54)$ & $40.23( \pm 9.7)$ & 0.6019 \\
\hline Weight $(\mathrm{kg})$ & $62.1( \pm 6.99)$ & $63.23( \pm 8.54)$ & 0.5771 \\
\hline Sex(males/females) & $13 / 17$ & $15 / 15$ & 0.6048 \\
\hline
\end{tabular}

Table 2: Intraoperative Mean Arterial Pressure and end tidal CO2

\begin{tabular}{|l|l|c|c|c|}
\hline \multicolumn{1}{|c|}{ Time } & \multicolumn{1}{c|}{ Parameter } & Group T & Group C & p-value \\
\hline Baseline & MAP* $(\mathrm{mm} \mathrm{Hg})$ & $72.86( \pm 5.07)$ & $74.16( \pm 6.33)$ & 0.3836 \\
\hline After induction & MAP & $81.9( \pm 5.62)$ & $82.83( \pm 7.49)$ & 0.588 \\
\hline $15 \mathrm{mins}$ & MAP & $67.16( \pm 3.66)$ & $68.26( \pm 3.49)$ & 0.238 \\
\hline $30 \mathrm{mins}$ & MAP & $68.46( \pm 3.70)$ & $69.46( \pm 3.3)$ & 0.2738 \\
\hline 45 mins & MAP & $66.86( \pm 2.83)$ & $68.36( \pm 3.65)$ & 0.0805 \\
\hline After induction & ETCO2\# & $40.06( \pm 3.61)$ & $39.56( \pm 3.5)$ & 0.5881 \\
\hline 15 mins & ETCO2 & $33.96( \pm 2.3)$ & $33( \pm 2.39)$ & 0.1184 \\
\hline 30 mins & ETCO2 & $31.5( \pm 2.38)$ & $32.03( \pm 2.02)$ & 0.3563 \\
\hline 45 mins & ETCO2 & $31.73( \pm 2.65)$ & $32.66( \pm 2.32)$ & 0.1535 \\
\hline
\end{tabular}

$* \mathrm{MAP}=$ mean arterial pressure, $\#+$ end tidal $\mathrm{CO} 2$. 
Table 3: Surgical field score

\begin{tabular}{|c|c|c|c|c|c|c|}
\hline Score* & \multicolumn{2}{|c|}{ 15 min } & \multicolumn{2}{c|}{ 30 min } & \multicolumn{2}{c|}{ 45 mins } \\
\hline & Group T & Group C & Group T & Group C & Group T & Group C \\
\hline 1 & 8 & 1 & 6 & 0 & 8 & 2 \\
\hline 2 & 16 & 9 & 17 & 6 & 18 & 10 \\
\hline 3 & 6 & 13 & 4 & 16 & 4 & 9 \\
\hline 4 & 0 & 7 & 3 & 8 & 0 & 9 \\
\hline 5 & - & - & - & - & - & - \\
\hline $\begin{array}{c}\text { P } \\
\text { value }\end{array}$ & \multicolumn{2}{|c|}{$<0.001$} & \multicolumn{2}{c|}{$<0.001$} & \multicolumn{2}{c|}{$<0.001$} \\
\hline
\end{tabular}

* = surgical field scale adapted from Boezaart et al.

Data expressed as number of patients in each category.

Table 4: Intraoperative blood loss and duration of surgery

\begin{tabular}{|l|c|c|c|}
\hline \multicolumn{1}{|c|}{ Parameter } & Group T & Group C & p-value \\
\hline $\begin{array}{l}\text { Estimated blood } \\
\text { Loss }(\mathrm{ml})\end{array}$ & $103.33( \pm 23.97)$ & $150.33( \pm 62.33)$ & $<0.001$ \\
\hline $\begin{array}{l}\text { Duration of surgery } \\
\text { (minutes) }\end{array}$ & $53.83( \pm 8.57)$ & $62.33( \pm 11.8)$ & 0.002 \\
\hline
\end{tabular}

\section{Discussion}

Nasal polyposis, chronic rhinosinusitis etc. are the important indications where FESS is increasingly being performed. However different pathologies have different propensities to bleed. We have included cases of nasal polyposis in our study.

Many methods are evaluated to create bloodless field during FESS like reverse Trendelenburg position ${ }^{3}$, topical vasoconstrictors ${ }^{4}$ steroids and manipulation of ventilator settings. ${ }^{3,5}$ Others like use of hypotensive agents such as beta blockers, magnesium sulphate, clonidine and sodium nitroprusside are also studied. ${ }^{1,6-10}$ All our patients were prepared with preoperative steroids and topical vasoconstrictor (Local infiltration with 5-6 $\mathrm{ml} 2 \%$ lignocaine with adrenaline) was given by surgeons. Intraoperatively we had given a $15^{\circ}$ head up position to all patients. The two other important factors that affect the quality of surgical field are mean arterial pressure and end tidal $\mathrm{CO} 2$. Both these factors were comparable in the two groups. Thus keeping both groups comparable for the above mentioned confounding factors, we have studied the additional benefit of intravenous bolus Tranexamic acid.

Tranexamic acid is a synthetic derivative of amino acid lysine. It inhibits the interaction of plasmiogen and heavy chain of plasmin with lysine residues on the surface of fibrin. Tranexamic acid induced suppression of fibrinolysis leads to reduction in blood levels of Ddimer. ${ }^{2}$ The drug has no effects on other coagulation parameters. ${ }^{11,12}$. The drug acts on the initial steps of fibrinolysis. Once the cascade phenomenon is set in, the efficacy of Tranexamic acid markedly decreases. So it is better if given before the incision for maximal effect. ${ }^{13-15}$ In our study we have given the drug during premedication, i.e. at least $10-15$ minutes before surgical incision was taken.
Blood loss both intraoperative and post operative during FESS is generally not a major consideration the blood loss averaging to less than $400 \mathrm{ml} .^{16,17}$ Rather it is the surgical field visualization that is of importance to surgeons. Duration of FESS surgeries is generally less than two hours, so we have given only a single bolus dose. The instruments and microdebriders used by surgeons and the surgical team were similar in both groups.

Authors have used various scales for grading surgical field like Wormald grading scale ${ }^{12}$ Boezaart scale, ${ }^{1} 10$ point visual analogue scale, ${ }^{18}$ etc. We have used Boezaart scale as it is easy to use and allows for minimum subjective variation.

Some other studies with some differences in format, have pointed out beneficial effects of Tranexamic acid when given during FESS..$^{19,16,2}$ A single bolus dose of $25 \mathrm{mg} / \mathrm{kg}$ and $10 \mathrm{mg} / \mathrm{kg}$ were used by Eldaba et $\mathrm{al}^{2}$ nd Khafagy et $\mathrm{al}^{19}$ respectively. The dose of $15 \mathrm{mg} / \mathrm{kg}$ that we have used is in the previously found effective range. In our study, 6 patients in group $\mathrm{T}$ had a Boezaart scale score of 3 or more i.e. had moderate to severe bleeding compromising surgical field and requiring suctioning as against 20 patients from group $\mathrm{C}$ at 15 minutes. Similarly at 30 minutes, 7 patients from group $\mathrm{T}$ and 24 patients from group $\mathrm{C}$ had a score of 3 or more. At 45 minutes, the number was 4 and 18 in group $\mathrm{T}$ and $\mathrm{C}$ group respectively. However no patient in any group had massive bleeding preventing dissection leading to abandoning of procedure. These findings are coherent with that of Eldaba et $\mathrm{al}^{2}{ }^{2}$ though the doses used by them were higher. Langille et $\mathrm{al}^{17}$ in their study using bolus as well as infusion of TA, found no improvement in surgical field. Both these studies have included patients having mixed disease types i.e. nasal polyposis as well as chronic sinusitis. Again it is not specified how much 
prior to incision was the drug administered. These factors may account for the effect seen in our study at the given dose.

This effect was also reflected in shorter surgical duration in the group receiving Tranexamic acid. There was also a reduced blood loss in Tranexamic acid group $(103.33 \pm 23.97 \mathrm{ml})$ as against group $\mathrm{C}(150.33 \pm 62.33$ $\mathrm{ml})$. However clinically, blood loss in neither group was significant enough to require blood replacement.

We have followed the patients till discharge and no signs and symptoms suggesting thrombotic complication was noted in them.

\section{Conclusion}

We found that when used as an adjunct, Tranexamic acid remarkably improved the surgical field visualization during Functional endoscopic sinus surgery.

\section{References}

1. Boezaart AP, van der Merwe J, Coetzee A. Comparison of sodium nitroprusside- and esmolol-induced controlled hypotension for functional endoscopic sinus surgery. Can J Anaesth 1995;42:373-6.

2. Eldaba AA, Amr YM, Albirmawy OA. Effects of tranexamic acid during endoscopic sinsus surgery in children. Saudi J Anaesth 2013;7:229-33.

3. Ko M-T, Chuang K-C, Su C-Y. Multiple analyses of factors related to intraoperative blood loss and the role of reverse Trendelenburg position in endoscopic sinus surgery. Laryngoscope. 2008;118(9):1687-91.

4. Cohen-Kerem R, Brown S, Villaseñor LV, Witterick I. Epinephrine/lidocaine injection vs. saline during endoscopic sinus surgery. Laryngoscope. 2008;118:127581.

5. Gilbey P, Kukuev Y, Samet A, Talmon Y, Ivry S. The quality of the surgical field during functional endoscopic sinus surgery--the effect of the mode of ventilation--a randomized, prospective, double-blind study.

Laryngoscope. 2009;119(12):2449-53.

6. Nair S, Collins M, Hung P, et al. The effect of betablocker premedication on the surgical field during endoscopic sinus surgery. Laryngoscope. 2004;114(6):1042-46.

7. Shen P-H, Weitzel EK, Lai J-T, Wormald P-J, Ho C-S Intravenous esmolol infusion improves surgical fields during sevoflurane-anesthetized endoscopic sinus surgery: a double-blind, randomized, placebo-controlled trial. Am J Rhinol Allergy. 2011;25(6):e208-11.

8. Elsharnouby NM, Elsharnouby MM. Magnesium sulphate as a technique of hypotensive anaesthesia. $\mathrm{Br} \mathrm{J}$ Anaesth. 2006;96(6):727-31.

9. Mohseni M, Ebneshahidi A. The effect of oral clonidine premedication on blood loss and the quality of the surgical field during endoscopic sinus surgery: a placebocontrolled clinical trial. J Anesth. 2011;25(4):614-7.

10. 10) Jacobi KE, Böhm BE, Rickauer AJ, Jacobi C, Hemmerling TM. Moderate controlled hypotension with sodium nitroprusside does not improve surgical conditions or decrease blood loss in endoscopic sinus surgery. Journal of Clinical Anesthesia. 2000;12(3):2027

11. Hoylaerts M, Lijnen HR, Collen D. Studies on the mechanism of the antifibrinolytic action of tranexamic acid. Biochim Biophys Acta 1981;673:75-85
12. Horrow JC, Van Riper DF, Strong MD, Grunewald KE, Parmet JL. The dose-response relationship of tranexamic acid. Anesthesiology 1995;82:383-92.

13. Tanaka N, Sakahashi H, Sato E, Hirose K, Ishima T, Ishii $\mathrm{S}$. Timing of the administration of tranexamic acid for maximum reduction in blood loss in arthroplasty of the knee. J Bone Joint Surg Br 2001;83:702-5.

14. Jansen AJ, Andreica S, Claeys M, D'Haese J, Camu F, Jochmans K. Use of tranexamic acid for an effective blood conservation strategy after total knee arthroplasty. Br J Anaesth 1999;83:596-601.

15. Sakahashi H, Sato E, Ishima T. A means for control of bleeding during and after the artificial knee joint replacement operation (combined use of antiplasmin and the drain clamp method). Jpn Soc Replace Arthroplasty 1998;28:67-8.

16. Alimian M, Mohseni M. The effect of intravenous tranexamic acid on blood loss and surgical field quality during endoscopic sinus surgery: A placebo-controlled clinical trial. J Clin Anesth 2011;23:611-5.

17. Langille MA, Chiarella A, Côté DWJ, et al. Intravenous tranexamic acid and intraoperative visualization during functional endoscopic sinus surgery: a double-blind randomized controlled trial. Int Forum Allergy Rhinol, 2013;3:315-8

18. Eberhart LHJ, Folz BJ, Wulf H, Geldner G. Intravenous anesthesia provides optimal surgical conditions during microscopic and endoscopic sinus surgery. Laryngoscope. 2003;113(8):1369-73.

19. Khafagy AH, Osman SM. Does tranexamic acid, deliberate hypotension, and anti-Trendelenburg position improve the quality and outcome for functional endoscopic sinus surgery. Egypt J Otolaryngol 2013;29:71-5 